NASA/TM-2011-216993

\title{
Hydrogen Reduction of Lunar Regolith Simulants for Oxygen Production
}

\section{U. Hegde and R. Balasubramaniam}

National Center for Space Exploration Research, Cleveland, Ohio

S.A. Gokoglu

Glenn Research Center, Cleveland, Ohio

K. Rogers, M. Reddington, and L. Oryshchyn

Johnson Space Center, Houston, Texas 


\section{NASA STI Program . . . in Profile}

Since its founding, NASA has been dedicated to the advancement of aeronautics and space science. The NASA Scientific and Technical Information (STI) program plays a key part in helping NASA maintain this important role.

The NASA STI Program operates under the auspices of the Agency Chief Information Officer. It collects, organizes, provides for archiving, and disseminates NASA's STI. The NASA STI program provides access to the NASA Aeronautics and Space Database and its public interface, the NASA Technical Reports Server, thus providing one of the largest collections of aeronautical and space science STI in the world. Results are published in both non-NASA channels and by NASA in the NASA STI Report Series, which includes the following report types:

- TECHNICAL PUBLICATION. Reports of completed research or a major significant phase of research that present the results of NASA programs and include extensive data or theoretical analysis. Includes compilations of significant scientific and technical data and information deemed to be of continuing reference value. NASA counterpart of peer-reviewed formal professional papers but has less stringent limitations on manuscript length and extent of graphic presentations.

- TECHNICAL MEMORANDUM. Scientific and technical findings that are preliminary or of specialized interest, e.g., quick release reports, working papers, and bibliographies that contain minimal annotation. Does not contain extensive analysis.

- CONTRACTOR REPORT. Scientific and technical findings by NASA-sponsored contractors and grantees.
- CONFERENCE PUBLICATION. Collected papers from scientific and technical conferences, symposia, seminars, or other meetings sponsored or cosponsored by NASA.

- SPECIAL PUBLICATION. Scientific, technical, or historical information from NASA programs, projects, and missions, often concerned with subjects having substantial public interest.

- TECHNICAL TRANSLATION. Englishlanguage translations of foreign scientific and technical material pertinent to NASA's mission.

Specialized services also include creating custom thesauri, building customized databases, organizing and publishing research results.

For more information about the NASA STI program, see the following:

- Access the NASA STI program home page at http://www.sti.nasa.gov

- E-mail your question via the Internet to help@ sti.nasa.gov

- Fax your question to the NASA STI Help Desk at $443-757-5803$

- Telephone the NASA STI Help Desk at 443-757-5802

- Write to: NASA Center for AeroSpace Information (CASI) 7115 Standard Drive Hanover, MD 21076-1320 
NASA/TM-2011-216993

AIAA-2011-0608

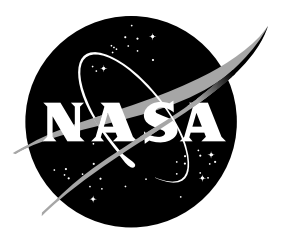

\section{Hydrogen Reduction of Lunar Regolith Simulants for Oxygen Production}

\section{U. Hegde and R. Balasubramaniam}

National Center for Space Exploration Research, Cleveland, Ohio

S.A. Gokoglu

Glenn Research Center, Cleveland, Ohio

K. Rogers, M. Reddington, and L. Oryshchyn

Johnson Space Center, Houston, Texas

Prepared for the

49th Aerospace Sciences Meeting

sponsored by the American Institute of Aeronautics and Astronautics

Orlando, Florida, January 4-7, 2011

National Aeronautics and

Space Administration

Glenn Research Center

Cleveland, Ohio 44135 


\section{Acknowledgments}

The authors gratefully acknowledge the support of this work by the In-Situ Resource Utilization Project which is a part of the NASA Exploration Technology Development Program. U. Hegde and R. Balasubramaniam were supported under NASA

Contract No. NNC08BA08B with the National Center for Space Exploration Research. The authors greatly appreciate the encouragement and insights offered by K. Sacksteder and D. Linne of NASA Glenn Research Center.

Trade names and trademarks are used in this report for identification only. Their usage does not constitute an official endorsement, either expressed or implied, by the National Aeronautics and Space Administration.

Level of Review: This material has been technically reviewed by technical management.

Available from

NASA Center for Aerospace Information 7115 Standard Drive

Hanover, MD 21076-1320
National Technical Information Service 5301 Shawnee Road Alexandria, VA 22312

Available electronically at http://www.sti.nasa.gov 


\title{
Hydrogen Reduction of Lunar Regolith Simulants for Oxygen Production
}

\author{
U. Hegde and R. Balasubramaniam \\ National Center for Space Exploration Research \\ Cleveland, Ohio 44135 \\ S.A. Gokoglu \\ National Aeronautics and Space Administration \\ Glenn Research Center \\ Cleveland, Ohio 44135 \\ K. Rogers, M. Reddington, and L. Oryshchyn \\ National Aeronautics and Space Administration \\ Johnson Space Center \\ Houston, Texas 77058
}

\begin{abstract}
Hydrogen reduction of the lunar regolith simulants JSC-1A and LHT-2M is investigated in this paper. Experiments conducted at NASA Johnson Space Center are described and are analyzed utilizing a previously validated model developed by the authors at NASA Glenn Research Center. The effects of regolith sintering and clumping, likely in actual production operations, on the oxygen production rate are studied. Interpretations of the obtained results on the basis of the validated model are provided and linked to increase in the effective particle size and reduction in the intra-particle species diffusion rates. Initial results on the pressure dependence of the oxygen production rate are also presented and discussed.
\end{abstract}

\section{Nomenclature}

$c_{o}$ molar concentration of hydrogen in regolith bed $\left(\operatorname{moles} / \mathrm{m}^{3}\right)$

$D$ effective gas diffusion coefficient $\left(\mathrm{m}^{2} / \mathrm{s}\right)$

$F$ factor defined by Equation (1) $\left(\mathrm{s}^{-1}\right)$

$k$ equilibrium constant

$L$ length of regolith bed (m)

$p$ gas pressure $(\mathrm{Pa})$

$r_{p}$ regolith particle radius $(\mathrm{m})$

$t$ time (s)

$t_{c}$ time for complete conversion (s)

$T$ temperature (K)

$u$ velocity through reactor $(\mathrm{m} / \mathrm{s})$

$\alpha$ particle conversion fraction

$\rho_{a}$ molar concentration of iron oxide in regolith $\left(\mathrm{mol} / \mathrm{m}^{3}\right)$ 


\section{Introduction}

A major objective of lunar in-situ resource utilization (ISRU) (Refs. 1 to 3 ) is production of oxygen from lunar regolith. Mare basalts containing oxygen include olivine, ilmenite, and pyroxene (Ref. 4). Energy has to be supplied to remove the oxygen, i.e., the associated chemical reactions are endothermic. Free energy considerations show that the iron containing minerals require the least energy input for this purpose (Ref. 5). Various technologies have been proposed for the chemical conversion. These include ilmenite reduction by hydrogen, molten electrolysis, and carbothermal reduction using methane (Refs. 6 and 7). The hydrogen reduction method targets the iron oxide in the regolith. Iron oxide occurs in lunar regolith as ilmenite, particularly in titanium-rich basalts, or may be found dispersed in the glassy phase of lunar regolith particles. The overall gas-solid reaction between $\mathrm{FeO}$ and hydrogen is given by:

$$
\mathrm{FeO}+\mathrm{H}_{2} \Leftrightarrow \mathrm{Fe}+\mathrm{H}_{2} \mathrm{O}
$$

The formed water may be electrolyzed in an electrolyzer subsystem to produce oxygen and recycle the hydrogen.

Hydrogen reduction systems are well developed for Earth applications but mainly for the purpose of metal extraction, as opposed to water vapor and oxygen extraction for lunar applications. In addition, in the lunar context, the reactor must interface with the other sub-system processes such as upstream regolith extraction and beneficiation and downstream electrolysis and phase separation in a way that establishes the most favorable balance between efficiency, robustness, and equivalent system mass. A need exists, therefore, to establish an analytical framework to couple these sub-systems together. The building blocks of this framework are the individual sub-system models. The development of a generalized analytical model of the chemical reactor sub-system and its validation against experimental data from reduction of JSC-1A, a lunar regolith simulant, has been discussed in an earlier paper (Ref. 8).

The primary objective of this paper is to investigate the hydrogen reduction of a new simulant, LHT-2M, which has been manufactured to resemble the highland type of lunar regolith, and to compare it with the hydrogen reduction of JSC-1A. To this end, experiments have been conducted at NASA Johnson Space Center for analysis with the validated model developed at NASA Glenn Research Center. This model (Ref. 8) is formulated in terms of the following overall steps: (i) inflow of pure hydrogen into the regolith containing reactor, (ii) reaction of hydrogen with the iron oxide portion of the regolith, and (iii) outflow of left-over hydrogen and produced water vapor. Step (ii) is the gas-solid reaction step which is the key to the conversion. Results of regolith particulate analysis conducted on Apollo-returned samples (Ref. 6) suggest that the particles are not dense solids but have some porosity that would enable gases to diffuse into the particles, i.e., the iron oxide portion can be essentially completely converted with the reduced iron remaining behind in the particulates. It may also be noted that both JSC-1A and LHT-2M have significant glass content with iron oxide dispersed in the glass phase. The diffusion of gases in the glass phase is expected to be the controlling feature for the reduction process. These observations support utilization of a "shrinking core" diffusion-reaction model (Ref. 9) for the gas-solid reduction process for the simulants. This model should be valid for lunar regolith as well if the gas diffusion in the particles remains the controlling step. The reaction model is coupled with the inflow/outflow of gases to complete the reactor sub-system model.

Two key parameters appear in the model: (i) a diffusion time related to the diffusion of gases in the interior of the regolith particles, and (ii) a residence time of the gases in the reactor. It is found that for high levels of conversion or for a relatively small ratio of residence time to diffusion time, the governing parameter is the diffusion time. Validation of the model was conducted by comparison to experiments carried out at Pacific Northwest National Laboratory (PNNL) (Ref. 10) and at Lockheed-Martin (Ref. 11) where the quantity of processed regolith simulant in the experiments was about three orders of magnitude larger than that used at PNNL. 
A factor $F$, which is inversely related to the diffusion times for different particle sizes, is derived from the model formulation (Ref. 8) and is defined as follows:

$$
F=6 \frac{c_{o}}{\rho_{a}} \frac{k}{(1+k)} \frac{D}{r_{p}^{2}}
$$

It was found, using the PNNL data for JSC-1A in conjunction with the model, that the factor $F$ may be correlated to the temperature by an Arrhenius expression:

$$
\log (F)=-\frac{10761}{T}-2.8808
$$

The above expression appears to work well for JSC-1A in the temperature range of 873 to $1273 \mathrm{~K}$, i.e., in between 600 and $1000{ }^{\circ} \mathrm{C}$, under atmospheric pressure conditions.

The factor $F$ depends upon the concentration of hydrogen, $c_{o}$, in the reactor, the intra-particle species diffusivity, $D$, the equilibrium constant, $k$, for the iron oxide reduction reaction, the concentration of iron oxide in the regolith/simulant, $\rho_{a}$, and the effective particle radius, $r_{p}$. The concentration, $c_{o}$, of hydrogen, provided that it is the sole inflow species, is proportional to the reactor pressure, $p$, assuming perfect gas behavior. The diffusion coefficient, $D$, will depend upon the regolith/simulant of interest and is, in general, a function of both reactor temperature, $T$, and pressure, $p$. The equilibrium constant, $k$, has generally been presumed to be a function of temperature alone and to be independent of pressure for the reduction of iron oxide with hydrogen (Ref. 8). Both $\rho_{a}$ and $r_{p}$ will depend upon the characteristics of the utilized regolith/simulant. It is clear therefore, that much work remains to be done to further characterize the variations in the factor $F$ for different regoliths and simulants and to understand the impact of reactor pressure.

It is also found that, apart from the dependencies noted above, regolith/simulant sintering and clumping during processing can impact the water production rate. A quantification of this effect is provided. In addition, some results on the pressure dependence of $F$, and hence of production rate, are also presented and discussed. In the following, a brief discussion of the developed model is provided first, and a description of the experimental apparatus and procedure is given next. This is followed by a presentation and discussion of the results.

\section{Model Description}

The shrinking core formalism (Ref. 9) is utilized in the model and is schematically depicted in Figure 1. Conversion proceeds from the exterior particle surface inward. As the reaction progresses into the interior of the particle, the reactant and product gases must diffuse through the particle matrix structure formed after the conversion.

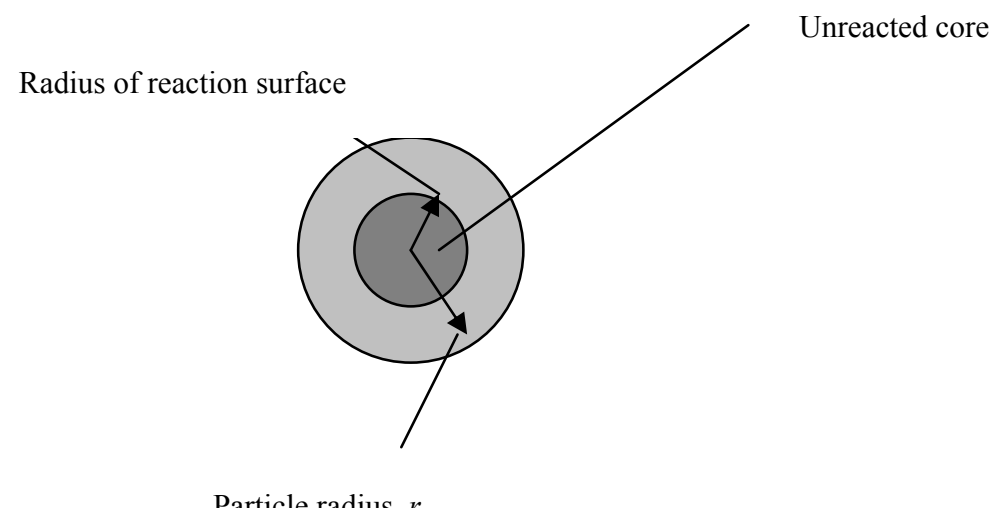

Figure 1.-Shrinking core model configuration. 
The equation for the conversion fraction $\alpha$ (related to the fraction of iron oxide converted) at a given time, $t$, is given by (Ref. 8)

$$
3[1-\alpha]^{2 / 3}-2[1-\alpha]-1=-\frac{F t}{\left[1+3(1-\varepsilon)\left(\frac{D}{r_{p}^{2}}\right) \frac{[1-\alpha]^{1 / 3}}{\left[1-(1-\alpha)^{1 / 3}\right]} \frac{L}{u}\right]}
$$

where the factor $F$ is given by Equation (1), $L$ is the length of the reactor bed, and $u$ is the gas velocity through the reactor. For the case when the residence time, $L / u$, of the gases is small compared to the diffusion time, $r_{p}{ }^{2} / D$, of gases in the particle matrix the equation for $\alpha$ becomes (Ref. 8)

$$
3[1-\alpha]^{2 / 3}-2[1-\alpha]-1=-F t
$$

It may be noted that the time required for high conversion (i.e., as $\alpha$ approaches unity) is also given by Equation (4). In practice, this means that unless the residence time is large compared to the diffusion time, the time for complete conversion is governed only by the diffusion time of the gases inside the particles. This implies that the factor $F$ is a characteristic descriptor of the reduction process. Examination of the expression for $F$ (see Eq. (1)) allows for the following observations:

(a) $F$ has units of inverse time (i.e., $\mathrm{s}^{-1}$ ).

(b) the equilibrium constant, $k$, is for Reaction (A) which is, presumably, not simulant dependent.

(c) the $\mathrm{FeO}$ concentration, $\rho_{a}$, is simulant dependent but should be relatively invariant from sample to sample or relative to the particle size of the same simulant.

(d) the hydrogen concentration, $c_{o}$, is relatively uniform in the reactor when the residence time is small compared to the diffusion time and is an operator controlled parameter of the experiment; it is a function of the reactor pressure, $p$, and temperature, $T$.

(e) the particle size, $r_{p}$, is an effective particle radius. There is generally no ambiguity about particle size for a relatively narrow size range; however, when the particle size range is broad, experiments need to be done to characterize a physically meaningful "effective" particle size.

(f) if the factors in (b) to (e) above are known, then $F$ may be directly related to $D$, the effective diffusion coefficient of the gases in the particle by Equation (1).

\section{Experiment Description}

An image of the reactor schematic and experimental set-up are shown in Figure 2. The reactor tube has an internal diameter of $2.12 \mathrm{~cm}$, an overall length of $76.2 \mathrm{~cm}$, and a test section (filter-to-filter) length of $22.9 \mathrm{~cm}$. It is constructed of Inconel 625 and is enclosed using flared T-fittings. A $50 \mu \mathrm{m}$ ceramically bonded alumina disk $(2.08 \mathrm{~cm}$ outer diameter by $0.32 \mathrm{~cm}$ inner diameter by $0.635 \mathrm{~cm}$ thick) is attached to a $0.32 \mathrm{~cm}$ thermocouple using compression ferrules to keep it from moving. The thermocouple and attached filter are inserted through the bottom T-fitting. A similar sintered metal filter is attached to a $0.32 \mathrm{~cm}$ rod through the top flared T-fitting. Together they serve to keep particulates from flowing out of the reactor and hold the simulant bed in place while allowing gas to pass through. Gas flows into and out of the reactor using the $90^{\circ}$ legs of the top and bottom T-fitting, respectively. The simulant is heated through the reactor walls using an external tube furnace. Temperature control is achieved using the internal thermocouple with the attached filter. The reactor is designed to withstand a temperature of $1323 \mathrm{~K}\left(1050{ }^{\circ} \mathrm{C}\right)$ at an absolute pressure of $4.4 \mathrm{~atm}$. Two mass flow controllers are used to set the desired gas flow rates of inert gas and hydrogen. Pressure transducers are installed on the inlet and outlet sides of the reactor to measure the pressure and pressure drop in the reactor. A flow meter and a back 




Figure 2.-Reactor schematic and experimental set-up.

pressure regulator placed downstream of the furnace complete the flow system. A relative humidity sensor, with an accuracy of 1 percent RH, is used to monitor the water concentration in the outflow gas. Water is removed from the outflow gas in a dryer. All data are recorded digitally.

A batch size of approximately $10 \mathrm{~g}$ of simulant is used for each test. A gas flow velocity of $1 \mathrm{~cm} / \mathrm{s}$ (as measured under atmospheric conditions) is utilized. Previous experiments suggested that this flow rate is generally sufficient to keep the simulant agitated and fluidized which is useful in preventing agglomeration and sintering of the particles during the test. However, sintering and clumping of the particles may occur if the fluidization is not isotropic, e.g., due to flow non-uniformities. The temperatures at which the reduction is carried out ranged between approximately 1023 to $1323 \mathrm{~K}$ (i.e., 750 to $1050{ }^{\circ} \mathrm{C}$ ). There is usually some bound water in the simulant sample which must be baked off prior to reduction in order to avoid ambiguity between reaction produced water and bound water. Thus, the test procedure is as follows:

1. Load reactor with simulant.

2. Flow inert gas, typically helium, while raising simulant to the test temperature.

3. Switch from inert gas to hydrogen flow after simulant has reached test temperature and evaporation of bound water is complete as evidenced by the humidity sensor data.

4. Continue hydrogen flow until weight loss from water production during reduction is below the humidity sensor accuracy threshold or for a maximum of $3 \mathrm{hr}$ whichever comes first.

5. Assess sintering and/or clumping of particles after test is complete.

The water output as a function of time is derived from the output of the relative humidity sensor. The dryer is weighed before and after heating the simulant to obtain the bakeout water amount. The dryer is also weighed after the completion of each test to obtain the overall amount of water produced by hydrogen reduction during the test. 


\section{Results and Discussion}

\section{A. Chemical Composition and Size Distribution Comparison of JSC-1A and LHT-2M}

The major constituents of JSC-1A and LHT-2M by weight percent, as obtained from their material safety data sheets, are shown in Table 1 and can be seen to be similar. A notable difference is the amount of iron oxide in the two simulants which is of interest in this study since hydrogen reduces mainly iron oxide in the temperature range of interest. The iron oxide generally consists of both $\mathrm{FeO}$ and $\mathrm{Fe}_{2} \mathrm{O}_{3}$. The maximum amount of water that can be obtained by hydrogen reduction of the oxides may be estimated based upon this composition. This is found to be approximately 2.8 and $1.2 \mathrm{wt} \%$ for JSC-1A and LHT-2M, respectively. It may be noted that this maximum amount of water that can be obtained from the hydrogen reduction of iron oxide corresponds to a conversion fraction, $\alpha$, of unity in Equations (3) and (4).

The particle size distributions of JSC-1A and LHT-2M, obtained from previous size sorting studies at NASA, are shown in Figure 3 which plots the cumulative mass percentage as a function of particle size. It is seen that the size distribution of the two simulants are very similar.

The similarities in the major chemical constituents of JSC-1A and LHT-2M suggests that the intraparticle species diffusivity may also be similar since hydrogen would need to diffuse through similar compositions (and, presumably, internal structures) to reach the dispersed iron oxide. In addition, the particle size distribution similarity suggests that the effective particle size, $r_{p}$, of both simulants should also be similar. The quantity, $\rho_{a}$, in Equation (1) is approximately a factor of three smaller for LHT-2M according to the reported concentration of iron oxide (Table 1). Referring to Equation (1), it is then reasonable to expect that under the same conditions of reactor temperature and pressure, the quantity $F$ will be of the same order for both JSC-1A and LHT-2M.

TABLE 1.-CHEMICAL COMPOSITION OF JSC-1A AND LHT-2M

\begin{tabular}{|l|c|c|}
\hline \multicolumn{1}{|c|}{ Composition } & Weight percent JSC-1A & Weight percent LHT-2M \\
\hline Silicon dioxide & 46 to 49 & 46.7 \\
\hline Aluminum oxide & 14.5 to 15.5 & 24.4 \\
\hline Calcium oxide & 10 to 11 & 13.6 \\
\hline Magnesium oxide & 8.5 to 9.5 & 7.9 \\
\hline Iron oxide & 10 to 11.5 & 4.16 \\
\hline Sodium oxide & 2.5 to 3 & 1.26 \\
\hline Potassium oxide & 0.75 to 0.85 & 0.08 \\
\hline Manganese oxide & 0.15 to 0.2 & 0.07 \\
\hline Titanium dioxide & 1 to 2 & 0.41 \\
\hline Phosphorous pentoxide & 0.6 to 0.7 & 0.15 \\
\hline
\end{tabular}

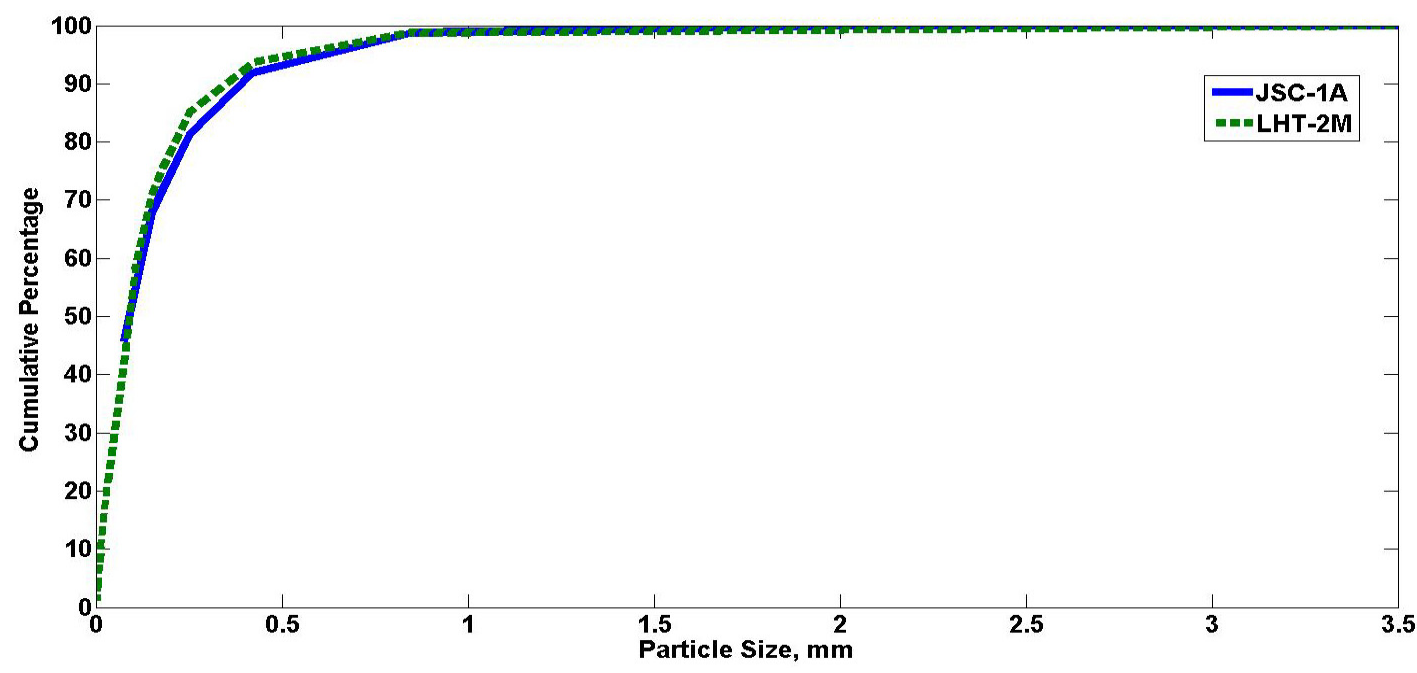

Figure 3.-Cumulative mass percentage of JSC-1A and LHT-2M as a function of particle size. 


\section{B. Effects of Sintering/Clumping on Reaction Rate}

In assessing the quantities that affect the factor $F$ and the water output rate, the sintering and/or clumping of the simulant particles has not been quantitatively addressed to date. Studies of sintering of lunar regolith and simulants have shown that softening of glass particles is the primary cause of sintering (Ref. 12). Sintering welds particles together due to viscous relaxation of the glass in the sample. As temperature increases, glass viscosity and time for sintering decrease. Experiments with Apollo 14 composition glass demonstrated (Ref. 13) that sintering can occur within minutes at temperatures of $1023 \mathrm{~K}\left(800^{\circ} \mathrm{C}\right)$ if the glass particles are otherwise undisturbed (e.g., by flow). Fluidization of the regolith bed decreases the amount of sintering as particles do not remain in contact with each other long enough for sintering to occur. It has also been found that smaller particles tend to sinter at earlier times compared to larger particles. This is summarized in Figure 4 which is taken from Cooper (Ref. 12) following Wosinski et al. (Ref. 13)

Referring to Equation (1), sintering maybe expected to modify both the effective particle size, $r_{p}$, and the effective species diffusivity $D$. It is clear that the effective size will increase as particles stick together and clumps are formed. As $r_{p}$ increases the value of $F$ will decrease. The impact on $D$ is more involved. The sticking of particles likely alters the path through which diffusion occurs tending to reduce the "porosity" and making the particles more impervious to mass transfer. This would indicate a reduction in $D$ and, consequently, a reduction in the value of $F$. Thus, the overall effect of sintering is expected to result in a decrease in the observed value of $F$, which, in turn, implies a reduction in the water production rate.

This assessment has been verified during the current experiment series. Though not expected based upon the discussions presented in Section IV.A., tests with LHT-2M at temperatures above 1173 K (i.e., $900{ }^{\circ} \mathrm{C}$ ) with batches that included particle sizes smaller than $125 \mu \mathrm{m}$ yielded values of $F$ that were substantially lower than those for correspondingly sized JSC-1A particles. Examination of these LHT-2M samples after reduction showed several sintered clumps, some of which were bigger than $1 \mathrm{~cm}$ in size. On the other hand, for unsieved LHT-2M which consists of a significant fraction of larger size particles (see Fig. 3) and for lower temperatures, the values of $F$ for JSC-1A and LHT-2M were comparable. Table 2 compares the values of $F$ for LHT-2M and JSC-1A for several cases showing this trend. Images of three of the post-reduction LHT-2M samples are shown in Figure 5 for both sintered and unsintered cases.

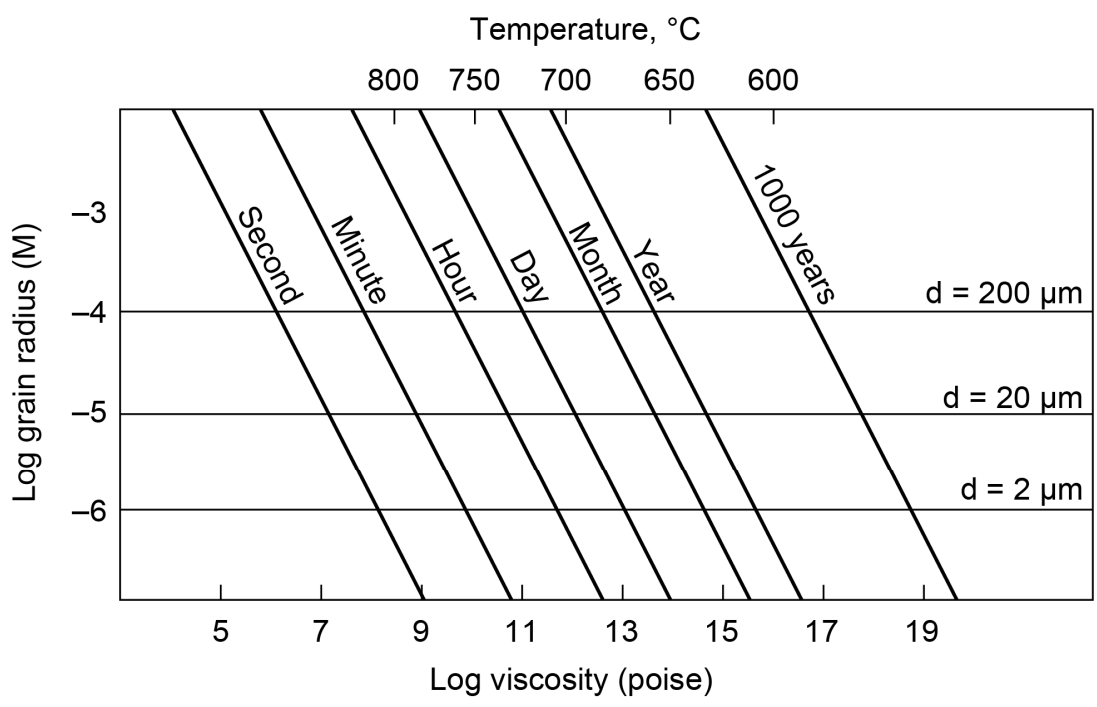

Figure 4.-Time for incipient sintering between two glass spheres deforming by viscous flow. (From Cooper (Ref. 12)). 
TABLE 2.-COMPARISON OF THE FACTOR $F$ FOR JSC-1A AND LHT-2M FOR DIFFERENT PARTICLE SIZE RANGES AND TEMPERATURES

\begin{tabular}{|l|c|c|c|}
\hline Particle size range & $\begin{array}{c}\text { Reduction temperature, } \\
\mathrm{K}\end{array}$ & $\begin{array}{c}F \text { for JSC-1A, } \\
\sec ^{-1}\end{array}$ & $\begin{array}{c}F \text { for LHT-2M, } \\
\text { sec }^{-1}\end{array}$ \\
\hline$<37 \mu \mathrm{m}$ & 1273 to 1323 & $6.7 \mathrm{e}^{-5}$ & $5.0 \mathrm{e}^{-7}$ (sintered) \\
\hline 40 to $75 \mu \mathrm{m}$ & 1273 to 1323 & $1.7 \mathrm{e}^{-5}$ & $9.0 \mathrm{e}^{-7}$ (sintered) \\
\hline Unsieved & 1273 to 1323 & $1.1 \mathrm{e}^{-5}$ & $1.1 \mathrm{e}^{-6}$ (sintered) \\
\hline Unsieved & 1173 to 1200 & $6.7 \mathrm{e}^{-6}$ & $2.8 \mathrm{e}^{-6}$ (partially sintered) \\
\hline Unsieved & 1048 to 1073 & $2.3 \mathrm{e}^{-6}$ & $3.1 \mathrm{e}^{-6}$ (unsintered) \\
\hline
\end{tabular}



(a)

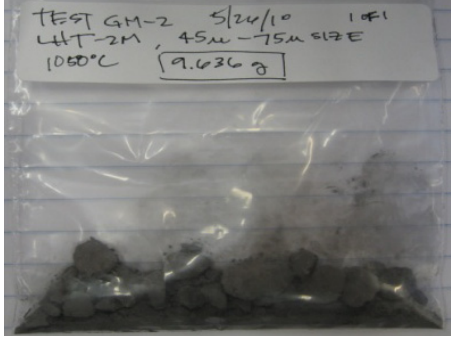

(b)

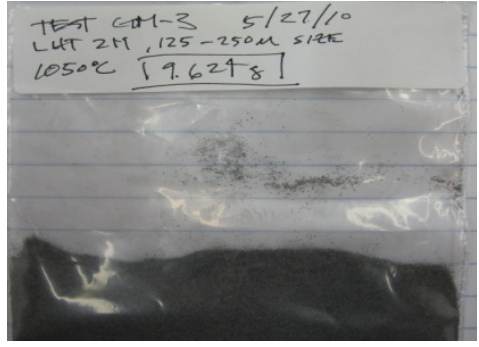

(c)

Figure 5.-Post reduction simulant samples (a) $<37 \mu \mathrm{m}$ (b) 40 to $75 \mu \mathrm{m}$ (c) 125 to $250 \mu \mathrm{m}$. Sintering and clumping is observed for (a) and (b) but not for (c). Reduction temperatures were between 1273 and $1323 \mathrm{~K}$ at $1 \mathrm{~atm}$ reactor pressure.

The sintering of LHT-2M in the current tests is believed to be due to non-isotropic fluidization of the simulant bed as was observed in other studies (Ref. 12). In order to verify this hypothesis, new experiments were conducted with JSC-1A which, in earlier tests using experimental hardware with different types of fluidization (Ref. 8), did not exhibit sintering up to temperatures of $1273 \mathrm{~K}\left(1000^{\circ} \mathrm{C}\right)$. Two tests were conducted with JSC-1A in the present set-up at reaction temperatures of $1273 \mathrm{~K}$ $\left(1000{ }^{\circ} \mathrm{C}\right)$ and $1073 \mathrm{~K}\left(800{ }^{\circ} \mathrm{C}\right)$, respectively. The post-reduced JSC-1A sample from the $1273 \mathrm{~K}$ test exhibited the clumping and sintering that was observed with LHT-2M. Figure 6 shows the experimental conversion with time for this test with the sintering effect present. Also shown in this figure are the expected range of conversion from our validated model predictions and data from a previous experiment conducted at Lockheed-Martin. The Lockheed-Martin experiment was a rotating reactor configuration in which the simulant did not exhibit sintering. It is seen that for the experiment conducted during the current study, the conversion rate (i.e., fraction converted in a given amount of time) is about 50 percent smaller than expected without sintering.

In contrast to the test case conducted at $1273 \mathrm{~K}$, the post-reduced JSC-1A sample from the $1073 \mathrm{~K}$ test did not have any observable sintering. The results from this test are shown in Figure 7. Also shown, as before, are the expected range of conversion from our validated model predictions as well as corresponding data from the Lockheed-Martin experiment. It is seen that the conversion rate from the current experiment agrees satisfactorily with the model estimate and prior experimental result.

While in the past, it has been suspected that sintering would result in lower conversion, this is the first time that this effect has been shown quantitatively and points to the importance of maintaining good fluidization and gas-solid particulates mixing in the reactor. It may be noted that non-uniformities in the inlet flow in the current reactor are believed to cause the non-isotropic fluidization and may be caused by blockages in the sintered plate of the inlet section. In addition, the observations here are consistent with previous findings (e.g., see Fig. 4) that sintering is promoted at the higher temperatures. 


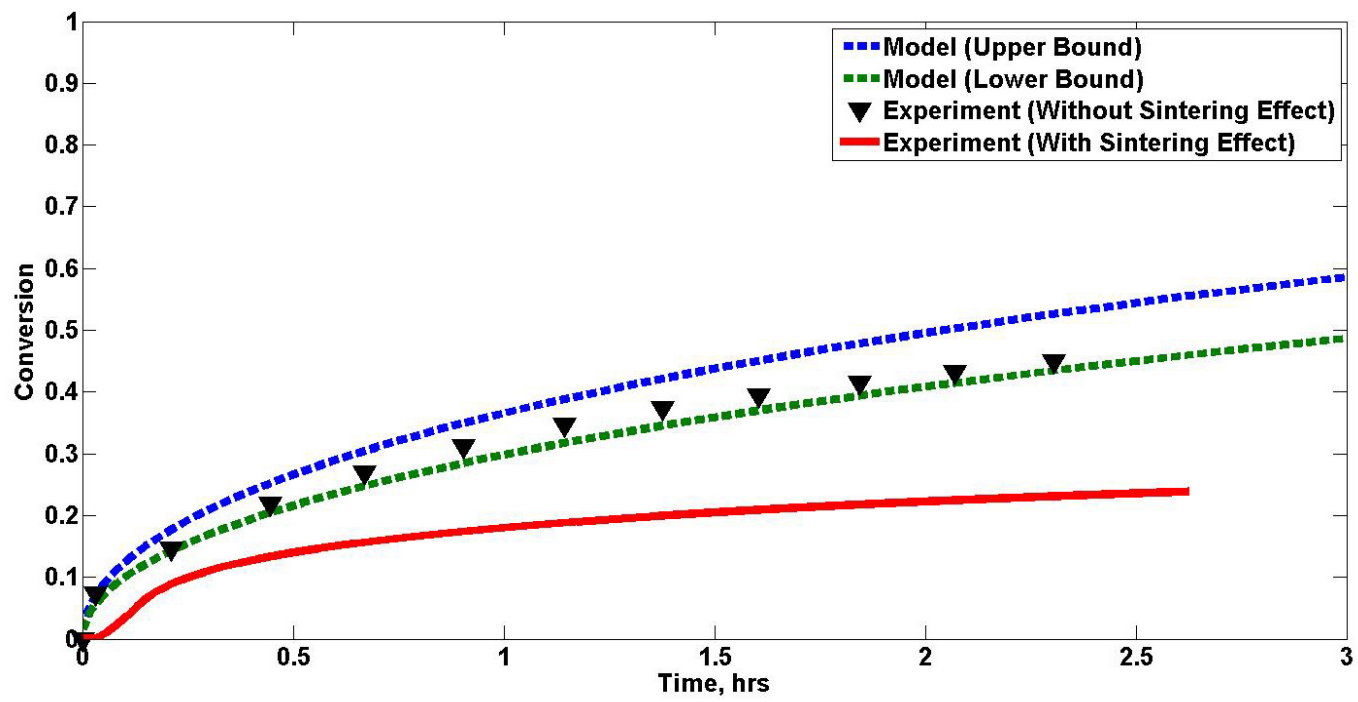

Figure 6. - The effect of sintering on the conversion of JSC-1A at $1273 \mathrm{~K}$.

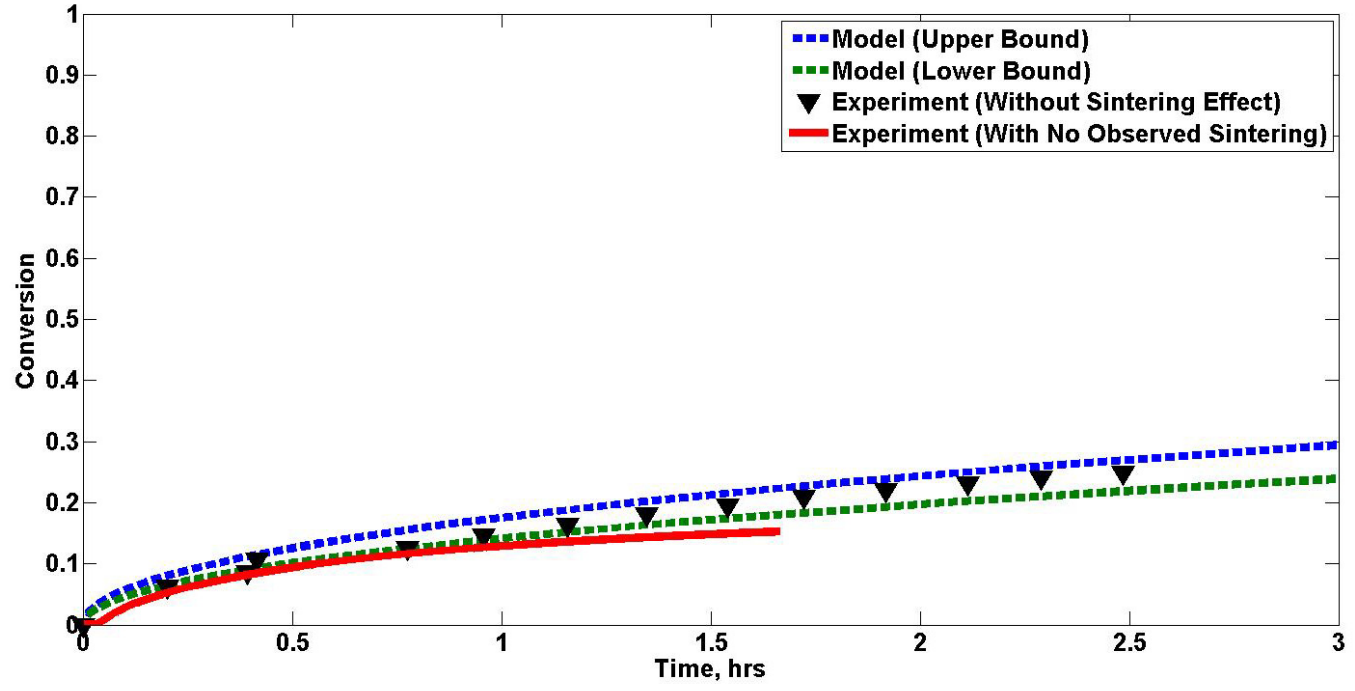

Figure 7.-Conversion of JSC-1A at $1073 \mathrm{~K}$. Effects of sintering are minimal. 


\section{Effect of Reactor Pressure}

Reactor pressure is expected to impact the factor $F$ through the concentration of hydrogen in the reactor, $c_{o}$, and the intra-particle species diffusivity $D$ as may be seen from Equation (1). In addition, it may be noted from Equation (4) that the time for complete conversion (i.e., $\alpha=1$ ) is given by

$$
t_{c}=\frac{1}{F}
$$

For given simulant characteristics and reaction temperature, and noting that the equilibrium constant may be assumed to be independent of pressure, as noted in the Introduction section, it is clear that $F$ is proportional to the product of the hydrogen concentration, $c_{o}$, and the effective species diffusivity, $D$

$$
F \propto c_{o} D
$$

so that the time for complete conversion becomes inversely proportional to this product

$$
t_{c} \propto\left(c_{o} D\right)^{-1}
$$

Since the inlet hydrogen concentration, $c_{o}$, is proportional to the reactor pressure, the conversion time becomes inversely proportional to the product of the pressure, $p$, and the diffusivity, $D$

$$
t_{c} \propto(p D)^{-1}
$$

The effect of reactor pressure for levels greater than atmospheric has been investigated in the current set of experiments using LHT-2M simulant particles in the 125 to $250 \mu \mathrm{m}$ size range. As noted earlier (e.g., see Fig. 5), particles in this size range did not exhibit sintering even at temperatures as high as 1273 to $1323 \mathrm{~K}$. This was found to be true even at pressures up to $3 \mathrm{~atm}$ which was the maximum reactor pressure tested. The experimentally observed conversion rates at 1 and $3 \mathrm{~atm}$ pressure and $1300 \mathrm{~K}$ are plotted in Figure 8 during the initial period of conversion for the larger, unsintered particles in the size range of 125 to $250 \mu \mathrm{m}$. Until approximately $0.25 \mathrm{hr}$, the conversion from the lower pressure case is

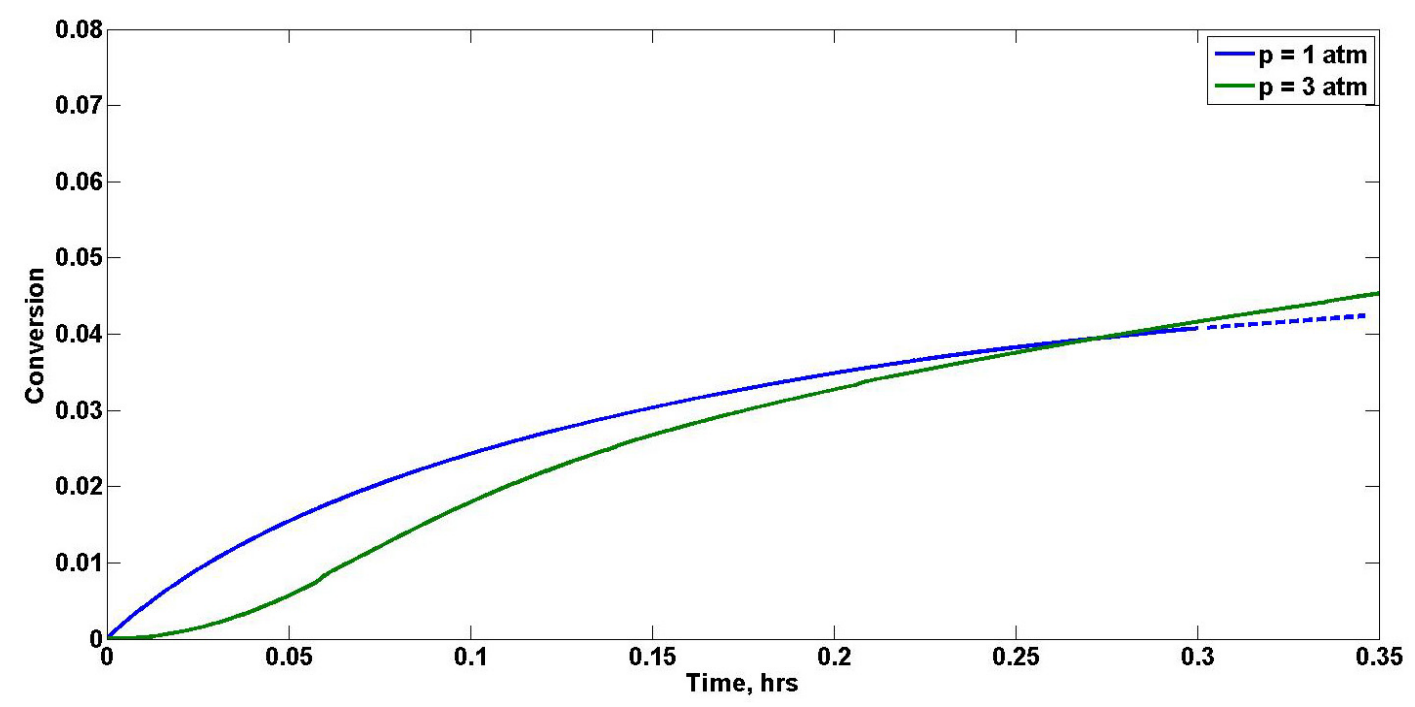

Figure 8.-Measured conversion as a function for 125 to $250 \mu \mathrm{m}$ size LHT-2M at 1 and 3 atm pressure at a temperature of $1300 \mathrm{~K}$. 
greater than that from the higher pressure case. Thereafter, the conversion from the higher pressure case is greater. In fact, for the lower $1 \mathrm{~atm}$ pressure case, the readings from the humidity sensor go below its sensitivity threshold at a conversion time of approximately $0.3 \mathrm{hr}$. This behavior may be explained by noting that during the initial period of conversion, the iron oxide in the surface layers of the particles are reduced. Diffusion rates in the bulk gas phase and inside the surface pores of the particles are likely important during this time and these are known to be inversely dependent upon the pressure.

The factor $F$ is estimated from the slope of the conversion versus time curve toward the end of the measurement period as has been discussed previously (Ref. 8). It is found that $F$ is about 50 percent larger for the $3 \mathrm{~atm}$ case compared to the $1 \mathrm{~atm}$ case. From the equations above, the pressure dependence of $D$ for this case may be shown to be

$$
D \propto p^{-0.63}
$$

A possible explanation for this finding is obtained by considering the mechanism of species diffusion in the interior of the simulant particles. If the diffusion process inside the particle is governed by gas phase processes alone $D$ would be inversely proportional to $p$. On the other hand, if diffusion of the species is through migration in the solid phase, the reactor pressure would not be expected to play a role implying that $D$ would be pressure independent. The $p^{-0.63}$ dependence of $D$, therefore, suggests that the species diffusion inside the simulant particles shares features from both gas phase and solid phase. This result is preliminary and more data are required at different particle sizes, reactor temperatures, and pressures to better establish the pressure dependence of the hydrogen reduction process. In this regard, it may be noted that in previous work at Lockheed-Martin, experiments with JSC-1A showed that the conversion rate was effectively doubled as reactor pressure increased from 0.5 to $1 \mathrm{~atm}$. Thus, at subatmospheric reactor pressures, the conversion time is proportional to $p$ which from the equation above suggests that the diffusivity $D$ is largely pressure independent, presumably due to being dominated by solid-phase diffusion.

\section{Conclusions}

The hydrogen reduction characteristics of LHT-2M, a lunar highlands regolith type simulant has been studied and compared with those of the simulant JSC-1A. Experiments were conducted in a tubular furnace reactor. Parameters varied were particle size, reaction temperature, and reactor pressure. Consistent with earlier studies on lunar regolith sintering, it was found that smaller particles and higher temperatures promoted clumping and sintering. The sintering/clumping resulted in significant (as much as 50 percent) reduction in the reaction rate. The deleterious effects of sintering were explained in terms of a model previously developed by the authors at NASA Glenn Research Center and were related to increase in the effective particle size and decrease in the effective intra-particle species diffusivity. The effects of reactor pressure on the reaction rate were also investigated. It was found that for pressures in the range of 1 to $3 \mathrm{~atm}$, the effective intra-particle species diffusivity varied as $p^{-0.63}$. The results of the present investigation will be useful for the design of proposed hydrogen reduction reactors.

\section{References}

1. Sanders, G.B., Larson, W.E., Sacksteder, K.R., and Mclemore, C., "NASA In-Situ Resource Utilization (ISRU) Project-Development \& Implementation," AIAA Paper No. 2008-7853, AIAA SPACE 2008 Conference \& Exposition, San Diego, California, September 2008.

2. Larson, W.E., Sanders, G.B., Sacksteder, K.R., Simon, T.M., and Linne, D.L., "NASA's In-Situ Resource Utilization Project: A Path to Sustainable Exploration," IAC-08-A3.2.B13, International Astronautical Congress, Glasgow, Scotland, October 2008. 
3. Sanders, G.B., Larson, W.E., Sacksteder, K.R., Simon, T.M., and Linne, D.L., "Open Architecture for Lunar Surface Systems-Challenges \& Opportunities In Design, Integration, and Partnerships," IAC08-D3.2.1, International Astronautical Congress, Glasgow, Scotland, October 2008.

4. Heiken, G.H., Lunar Sourcebook, Cambridge University Press, NY, 1991.

5. Taylor, L.A., and Carrier, W.D. III, "Production of Oxygen on the Moon: Which Processes are Best and Why," AIAA Journal, 30, (12), 2858-2863, (1992).

6. McKay, D.S., and Allen, C.C., "Hydrogen Reduction of Lunar Materials for Oxygen Extraction on the Moon," AIAA Paper No. 96-0488, American Institute of Aeronautics and Astronautics, Washington, DC, 1996.

7. Rice, E.E., Hermes, P.A., and Musbah, O.A., "Carbon Based Reduction of Lunar Oxides for Oxygen Production,” AIAA Paper No. 97-0890, American Institute of Aeronautics and Astronautics, Washington, DC, 1997.

8. Hegde, U., Balasubramaniam, R., and Gokoglu, S., "Development and Validation of a Model for Hydrogen Reduction of JSC-1A," NASA/TM-2009-215618, May 2009.

9. Levenspiel, O., Chemical Reaction Engineering, Wiley, NY, 1972.

10. Dagle, R., Holladay, J., Wilcox, W., and Wegeng, R., "Application of Microtechnology to NASA: Regolith Reduction Task Update," Pacific Northwest National Laboratory Report, Project\# 52199, August 2007.

11. Clark, D.L., "Integrated In-Situ Resource Utilization for Human Exploration-Propellant Production for the Moon and Beyond," Monthly Report, Lockheed Martin LOP-2005-0102, August 2007.

12. Cooper, B.L., "Sintering of Lunar and Simulant Glass," Proceedings of the Space Technologies and Applications International Forum, Albuquerque, New Mexico, February 2005.

13. Wosinski, J.F., Williams, J.P., Korda, E.J., Kane, W.T., Carrier, G.B., and Schreurs, J.W.H., "Inclusions and Interface Relationships Between Glass and Breccia in Lunar Sample 14306,50," Proceedings of Lunar Science III, Lunar Science Institute, Houston, 809-813, 1972. 


\begin{tabular}{|c|c|c|c|c|c|}
\hline \multicolumn{5}{|c|}{ REPORT DOCUMENTATION PAGE } & $\begin{array}{c}\text { Form Approved } \\
\text { OMB No. 0704-0188 }\end{array}$ \\
\hline \multicolumn{6}{|c|}{ 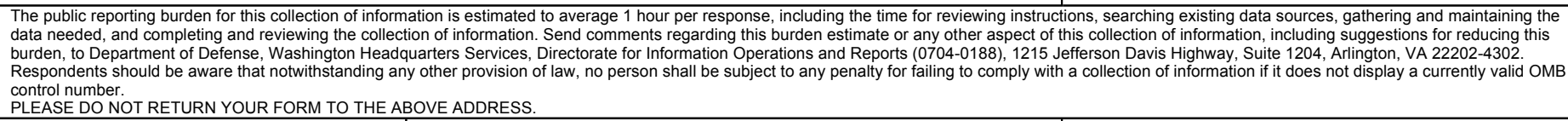 } \\
\hline \multicolumn{2}{|c|}{$\begin{array}{l}\text { 1. REPORT DATE (DD-MM-YYYY) } \\
01-03-2011\end{array}$} & \multicolumn{3}{|c|}{$\begin{array}{l}\text { 2. REPORT TYPE } \\
\text { Technical Memorandum }\end{array}$} & 3. DATES COVERED (From - To) \\
\hline \multirow{3}{*}{\multicolumn{5}{|c|}{$\begin{array}{l}\text { 4. TITLE AND SUBTITLE } \\
\text { Hydrogen Reduction of Lunar Regolith Simulants for Oxygen Production }\end{array}$}} & 5a. CONTRACT NUMBER \\
\hline & & & & & 5b. GRANT NUMBER \\
\hline & & & & & 5c. PROGRAM ELEMENT NUMBER \\
\hline \multirow{3}{*}{\multicolumn{5}{|c|}{$\begin{array}{l}\text { 6. AUTHOR(S) } \\
\text { Hegde, U.; Balasubramaniam, R.; Gokoglu, S., A.; Rogers, K.; Reddington, M.; Oryshchyn, } \\
\text { L. }\end{array}$}} & 5d. PROJECT NUMBER \\
\hline & & & & & 5e. TASK NUMBER \\
\hline & & & & & $\begin{array}{l}\text { 5f. WORK UNIT NUMBER } \\
\text { WBS 387498.04.01.05.02.03 }\end{array}$ \\
\hline \multicolumn{5}{|c|}{$\begin{array}{l}\text { 7. PERFORMING ORGANIZATION NAME(S) AND ADDRESS(ES) } \\
\text { National Aeronautics and Space Administration } \\
\text { John H. Glenn Research Center at Lewis Field } \\
\text { Cleveland, Ohio 44135-3191 }\end{array}$} & $\begin{array}{l}\text { 8. PERFORMING ORGANIZATION } \\
\text { REPORT NUMBER } \\
\text { E-17632 }\end{array}$ \\
\hline \multirow{2}{*}{\multicolumn{5}{|c|}{$\begin{array}{l}\text { 9. SPONSORING/MONITORING AGENCY NAME(S) AND ADDRESS(ES) } \\
\text { National Aeronautics and Space Administration } \\
\text { Washington, DC 20546-0001 }\end{array}$}} & $\begin{array}{l}\text { 10. SPONSORING/MONITOR'S } \\
\text { ACRONYM(S) } \\
\text { NASA }\end{array}$ \\
\hline & & & & & $\begin{array}{l}\text { 11. SPONSORING/MONITORING } \\
\text { REPORT NUMBER } \\
\text { NASA/TM-2011-216993 }\end{array}$ \\
\hline \multicolumn{6}{|c|}{$\begin{array}{l}\text { 12. DISTRIBUTION/AVAILABILITY STATEMENT } \\
\text { Unclassified-Unlimited } \\
\text { Subject Category: } 31 \\
\text { Available electronically at http://www.sti.nasa.gov } \\
\text { This publication is available from the NASA Center for AeroSpace Information, 443-757-5802 }\end{array}$} \\
\hline \multicolumn{6}{|c|}{ 13. SUPPLEMENTARY NOTES } \\
\hline \multicolumn{6}{|c|}{$\begin{array}{l}\text { 14. ABSTRACT } \\
\text { Hydrogen reduction of the lunar regolith simulants JSC-1A and LHT-2M is investigated in this paper. Experiments conducted at NASA } \\
\text { Johnson Space Center are described and are analyzed utilizing a previously validated model developed by the authors at NASA Glenn } \\
\text { Research Center. The effects of regolith sintering and clumping, likely in actual production operations, on the oxygen production rate are } \\
\text { studied. Interpretations of the obtained results on the basis of the validated model are provided and linked to increase in the effective particle } \\
\text { size and reduction in the intra-particle species diffusion rates. Initial results on the pressure dependence of the oxygen production rate are } \\
\text { also presented and discussed. }\end{array}$} \\
\hline \multicolumn{6}{|c|}{$\begin{array}{l}\text { 15. SUBJECT TERMS } \\
\text { Hydrogen reduction; Lunar in-situ resource utilization (ISRU); Lunar regolith simulant; Lunar regolith; Lunar simulant }\end{array}$} \\
\hline \multicolumn{3}{|c|}{ 16. SECURITY CLASSIFICATION OF: } & $\begin{array}{l}\text { 17. LIMITATION OF } \\
\text { ABSTRACT }\end{array}$ & $\begin{array}{l}\text { 18. NUMBER } \\
\text { OF }\end{array}$ & $\begin{array}{l}\text { 19a. NAME OF RESPONSIBLE PERSON } \\
\text { STI Help Desk (email:help@sti.nasa.gov) }\end{array}$ \\
\hline $\begin{array}{l}\text { a. REPORT } \\
\text { U }\end{array}$ & $\begin{array}{l}\text { b. ABSTRACT } \\
\text { U }\end{array}$ & $\begin{array}{l}\text { c. THIS } \\
\text { PAGE } \\
\text { U }\end{array}$ & UU & $\begin{array}{l}\text { PAGES } \\
18\end{array}$ & $\begin{array}{l}\text { 19b. TELEPHONE NUMBER (include area code) } \\
443-757-5802\end{array}$ \\
\hline
\end{tabular}



